\title{
Medium Absorption Reticulocyte Measurement
}

National Cancer Institute

\section{Source}

National Cancer Institute. Medium Absorption Reticulocyte Measurement. NCI

Thesaurus. Code C116192.

The determination of the amount of medium absorption reticulocytes present in a sample. 